\title{
Legal protests prompt DNA primer release
}

\section{Paul Smaglik, Washington}

A leading supplier of DNA testing kits widely used in legal actions has promised to make public its closely held proprietary information on the sequence of the primer used in the kits.

In a number of recent cases, defence attorneys have successfully challenged the validity of DNA testing on the grounds of lack of access to such information. The companies that make the tests have withheld the information through commercial confidentiality. However, the market for such tests could diminish if they are rendered legally invalid.

On 18 April, for example, a state court in Vermont ruled that DNA results were inadmissible as evidence in a criminal case because the two main companies that had provided the tests - Promega and PE Biosystems - had not made their primer sequences available. Last week, Promega said it will divulge those sequences in future.

To establish whether crime-scene DNA samples match those from suspects, forensic scientists analyse DNA from points in the genome at which the letters in the genetic code repeat, focusing on 13 sites where the number of repeats varies highly between individuals. The primers are designed to

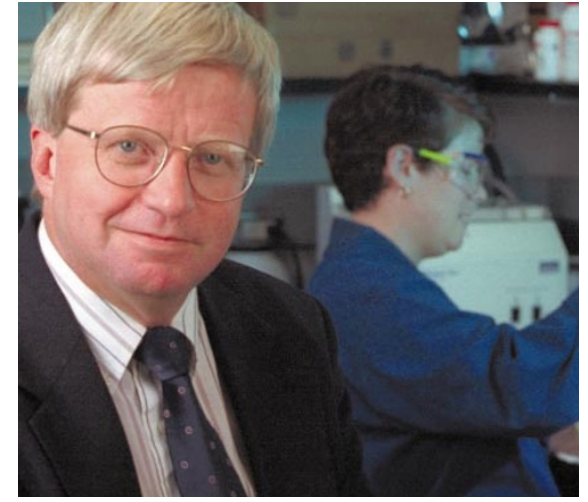

Mozer: revealing sequences will remove doubt.

bind to the sequences flanking these repeating regions, allowing scientists to multiply the repeated regions over and over again using the polymerase chain reaction.

This amplification process enables scientists to count the number of repeats in both the evidence and the suspect's DNA sample. If the number of repeats in each of the 13 regions matches, it is highly likely that the two samples came from the same individual.

Some defence attorneys have recently argued successfully that, in principle, the primers could contaminate the DNA being amplified, invalidating the test. Without knowing the sequence of the primers, however, courts cannot determine whether the primer sequence is present in the samples.

Promega researcher Tom Mozer says the chances of contamination are extremely remote. But defence attorneys have used the lack of disclosure to introduce doubt into the proceedings. Releasing the primer sequences will help dispel that doubt, Mozer says.

Arthur Eisenberg, director of the DNA Identity Laboratory at the University of North Texas Health Science Center in Fort Worth, agrees that contamination from primers is rare. "It's an argument that the defence has used to try to keep this testimony out of court," he claims.

While applauding Promega's decision to release the information, he speculates that the company may be hoping forensic scientists will turn to its tests rather than its competitors' because they stand a better chance of being accepted in court.

And although Promega is divulging valuable intellectual property, Eisenberg doubts that many scientists will bother to copy them all. Although it is feasible to create one or two primers by hand, a complete pre-prepared set is far more useful.

\section{Review panel assails Brussels research bureaucracy}

\section{Quirin Schiermeier, Munich}

European scientists have long griped about the bureaucracy and delays involved in extracting funds from the European Commission. Their complaints have now been endorsed by an independent advisory panel that says improvements are essential if the commission is to achieve its goals.

A survey carried out for the panel found that only $70 \%$ of participants in the commission's Framework research programmes thought the benefits had

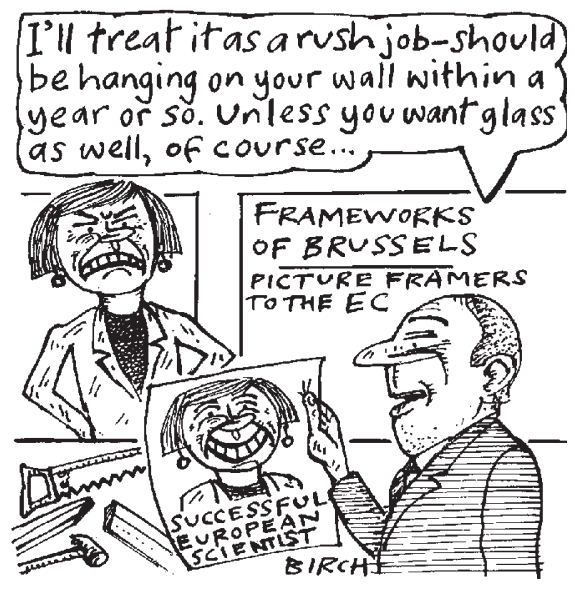

outweighed the costs. Two-thirds complained that the application process was too slow and/or costly, and $45 \%$ found the application procedures difficult to follow.

The panel says that the Framework programme is unable to meet the coordinated science-policy goals outlined by the heads of government at a summit meeting in Lisbon last spring, intended to make Europe the world's most dynamic and competitive knowledge-based economy.

The commission sets up the panel every five years to evaluate its Framework programmes. Academics and industrialists from 11 countries carried out the 1995-99 assessment, chaired by Joan Majó, a former Spanish minister for industry.

The panel's main recommendation is that the administration of the Framework programme should be aligned with the practical needs of European scientists and industry. Its criticism of application procedures is based on the analysis of 2,275 responses to a survey of applicants to the third and fourth Framework programmes.

Scientists participating in the current fifth Framework programme (FP5) have

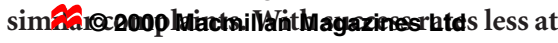
than $20 \%$ in some sub-programmes, many researchers wonder whether applying is worth the effort (see Nature 404, 695; 2000).

Panel member Yves Farge, special adviser to France's Centre National de la Recherche Scientifique, says the programmes' inefficiency is due mostly to cumbersome administrative procedures. "It is time now to react and to simplify the rules," he says.

Commission officials are already exploring improvements to the application and evaluation procedure. Some of these will be tested next February in a pilot call for proposals in bioethics and the socioeconomic aspects of biological research.

The commission is also considering changing the rule that FP5 grant proposals must be anonymous during the first stage of evaluation. Although intended to prevent biased evaluation, many scientists say that it has serious drawbacks. For example, the inability to cite their previous publications makes it hard for research groups to show that their work is truly innovative.

The panel also calls on the commission to encourage more proposals for high-risk, high-return projects. "The stock of groundbreaking new ideas developed in the 1990s will not last for ever," says Farge.

http://www.cordis.lu/fp5/5yr_reports.htm 